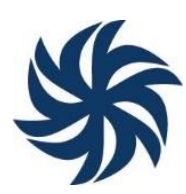

\title{
AVALIAÇÃo DA IMPLEMENTAÇÃO DA POLÍTICA ESTADUAL DE RESÍDUOS SÓLIDOS EM ALAGOAS POR MEIO DA EXECUÇÃO ORÇAMENTÁRIA E FINANCEIRA
}

\author{
ANALYZE OF IMPLEMENTATION OF STATE POLICY ON SOLID WASTE IN \\ ALAGOAS BY BUDGETARY AND FINANCIAL IMPLEMENTATION \\ EVALUACIÓN DE LA APLICACIÓN DE LA POLÍTICA ESTATAL DE RESIDUOS \\ SÓLIDOS EN ALAGOAS POR IMPLEMENTACIÓN PRESUPUESTARIA Y \\ FINANCIERA
}

\author{
Deivdson Brito Gatto* \\ Maria Cecília Junqueira Lustosa**
}

\begin{abstract}
Resumo: O artigo tem por objetivo avaliar como o planejamento e a execução orçamentária influenciaram a efetivação da Política Nacional de Resíduos Sólidos em Alagoas, com ênfase na Lei Estadual $n^{\circ}$ $7.749 / 2015$, que implementou a política no estado. Foi realizada uma pesquisa exploratória e descritiva com foco na execução orçamentária e financeira da referida política estadual através da análise dos Planos Plurianuais (PPA) de 2008-2011, 2012-2015 e 2016-2019; as Leis Orçamentárias Anuais (LOA) de 2008 a 2018 e os Balanços do governo do estado de 2008 a 2017. Como resultado, ficou constatado que o governo estadual conseguiu realizar um terço dos gastos previstos nas dotações orçamentárias do período, o que provavelmente se reflete na operacionalização de somente três dos sete consórcios criados para destinação dos resíduos sólidos em Alagoas. Mesmo assim, o objetivo de eliminação dos lixões nos municípios alagoanos foi atingido com três Centrais de Tratamento de Resíduos Sólidos atendendo à demanda das sete regiões do estado.
\end{abstract}

Palavras-chave: Política Nacional de Resíduos Sólidos; Alagoas; Plano Plurianual; Lei Orçamentária Anual e Balanço Orçamentário.

\begin{abstract}
The article aims to evaluate how the budgetary planning and execution influenced the implementation of the National Solid Waste Policy in Alagoas, with emphasis on State Law No. 7749/2015, which implemented the policy in the state. An exploratory and descriptive research was carried out focusing on the budgetary and financial execution of this state policy through the analysis of the Pluriannual Plans (PPA) 2008-2011, 2012-2015 and 2016-2019; the Annual Budget Laws (LOA) from 2008 to 2018 and the state government's balance sheets from 2008 to 2017. As a result, it was found that the state government was able to realize one-third of the estimated budget expenditures for the period, which is probably reflected in the operationalization of only three of the seven consortia created for the disposal of solid waste in Alagoas. Nevertheless, the objective of eliminating garbage dumps in the municipalities of Alagoas was achieved with three Solid Waste Treatment Centers meeting the demand of the seven regions in the state.
\end{abstract}

Key words: National Policy on Solid Waste; Alagoas; Plurianual Plan; Annual Budget Law; Budgetary Balance.

\footnotetext{
*Doutorando em Políticas Públicas, Estratégias e Desenvolvimento. Instituto de Economia. UFRJ. E-mail: deivdson@gmail.com. ORCID iD: https://orcid.org/0000-0001-8339-6351.

** Professora titular da Faculdade de Economia, Administração e Contabilidade. Universidade Federal de Alagoas (UFAL). E-mail: cecilialustosa@gmail.com
} 
Resumen: El artículo tiene como objetivo evaluar cómo la planificación y ejecución del presupuesto influyó en la implementación de la Política Nacional de Residuos Sólidos en Alagoas, con énfasis en la Ley Estatal No. 7,749 / 2015, que implementó la política en el estado. Se realizó una investigación exploratoria y descriptiva centrada en la ejecución presupuestaria y financiera de dicha política estatal a través del análisis de los Planes Plurianuales (PPA) 2008-2011, 2012-2015 y 2016-2019; las Leyes de Presupuesto Anual (LOA) de 2008 a 2018 y las Hojas de Balance del Gobierno del Estado de 2008 a 2017. Como resultado, se descubrió que el Gobierno del Estado pudo hacer un tercio del gasto presupuestario planificado para el período, lo que probablemente se refleje en en la operacionalización de solo tres de los siete consorcios creados para la eliminación de residuos sólidos en Alagoas. Aun así, el objetivo de la eliminación de vertederos en los municipios de Alagoas se logró con tres Centros de Tratamiento de Residuos Sólidos que satisfacen la demanda de las siete regiones del Estado.

Palabras clave: Política nacional sobre residuos sólidos; Alagoas; Plan plurianual; Ley de Presupuesto Anual y Balance Presupuestario.

\section{Introdução}

A Política Nacional de Resíduos Sólidos (PNRS) foi estabelecida na forma da Lei ${ }^{\circ}$ 12.305/2010 de agosto de 2010. Dentre os instrumentos instituídos na política está a elaboração dos Planos de Resíduos Sólidos, condição para que estados e municípios possam ter acesso tanto aos recursos da União, ou por ela controlados, destinados a empreendimentos e serviços relacionados à gestão de resíduos sólidos, quanto aos incentivos ou financiamentos de entidades federais de crédito ou fomento para tal finalidade. Além disso, a política prioriza o acesso aos recursos da União aos estados que instituírem microrregiões para integrar a organização, o planejamento e a execução das ações a cargo de municípios limítrofes na gestão dos resíduos sólidos.

Em Alagoas, a Política Estadual de Resíduos Sólidos (PERS) foi instituída pela Lei $\mathrm{n}^{\circ}$ 7.749/2015 em outubro de 2015 e o respectivo Plano Estadual de Resíduos Sólidos (PERS) em janeiro de 2016. Após dois anos, 2018, o estado conseguiu encerrar todos os lixões a céu aberto existentes nos municípios alagoanos, se tornando o primeiro estado nordestino e o terceiro do país a eliminar $100 \%$ dos lixões. O feito levanta vários questionamentos em torno da execução da política de resíduos sólidos no território brasileiro: como Alagoas conseguiu finalizar esses espaços de concentração de lixo em apenas dois anos? Quais os antecedentes da política? Qual estratégia foi utilizada? Como o gasto ocorreu e foram concentrados? Quais os maiores gastos, despesas correntes ou de capital? E as fontes, concentrados em recursos ordinários ou vinculados?

Nesse contexto, o artigo tem por objetivo analisar como o planejamento e a execução orçamentária influenciaram a implementação da política de resíduos sólidos no estado de Alagoas. Para alcançar esse objetivo, foram identificados e analisados os instrumentos utilizados pelo governo estadual e sua execução orçamentária por meio de consulta ao Sistema de Planejamento e Orçamento do estado: Plano Plurianual (PPA) - instrumento de médio prazo; Lei de Diretrizes 
Orçamentárias $(\mathrm{LDO})^{1}$ - parâmetros e eventos que podem afetar as variáveis fiscais; e Lei Orçamentária Anual (LOA) - alocação dos recursos necessários para cumprimento das obrigações dos entes federados. Por último, foi verificada a apuração do gasto da política em análise através da verificação dos Balanços Orçamentários.

Foram utilizadas duas técnicas de pesquisa: exploratória e descritiva. A utilização da primeira buscou proporcionar uma visão geral da política nacional de resíduos sólidos, por meio de um estudo de caso, através da análise da implementação da referida política no estado de Alagoas. Para atingir esse fim, foi realizada uma pesquisa bibliográfica sobre a temática e análise de dados secundários divulgados pelo governo de Alagoas. Na segunda técnica, procurou-se descrever as relações entre o cumprimento das metas do plano estadual de resíduos sólidos (PERS) e a execução orçamentária e financeira. Para isso, foram analisados os PPA de 20082011, 2012-2015 e 2016-2019; as LOAs de 2008 a 2018 e os Balanços de 2008 a 2017 do governo do estado de Alagoas. Os valores apresentados no trabalho foram inflacionados para o ano de 2018, para abstrair a variação do poder aquisitivo do Real (R\$) e captar se a variação se deve a um aumento real dos gastos na política.

O artigo está divido em seis seções incluindo essa introdução. A próxima seção apresenta uma breve abordagem sobre os aspectos teóricos que envolvem a construção de políticas públicas, planejamento e orçamento no Brasil e como a questão federativa molda a prestação dos serviços públicos no país. A seção 3 traça um panorama da PNRS no Brasil até 2017. Na quarta seção é apresentada a implementação da PERS no estado de Alagoas em 2015, seus antecedentes e posteriores desdobramentos. A quinta seção expõe a análise da execução orçamentária e financeira da PERS de Alagoas entre 2008 e 2018. E a última seção apresenta as considerações finais.

\section{Políticas públicas, planejamento e federalismo fiscal}

Uma política pública é qualquer ação do governo com objetivo de alterar uma dada realidade social (TRONCO, 2018). Dada a multiplicidade de definições, Souza (2006) acredita que não existe um conceito único para o termo, mas sintetiza que esse campo do conhecimento busca “[...] colocar o governo em ação" e/ou analisar essa ação (variável independente) e, quando necessário, propor mudanças no rumo ou curso dessas ações (variável dependente)" (SOUZA, 2006 p. 26). Em uma perspectiva mais operacional, Saravia (2006) define o termo como uma decisão pública, ação ou omissão, preventiva ou corretiva, que pretende manter ou modificar o status quo de um ou vários aspectos da vida social, através de objetivos e estratégias definidas por meio da alocação de recursos para atingir seu fim. $\mathrm{O}$ autor introduz no conceito um elemento

\footnotetext{
${ }^{1}$ As LDO do período analisado foram consultadas, no entanto, o texto fica concentrado nas diretrizes para elaboração do orçamento anual: estrutura e organização, diretrizes para execução e apresentação de metas e prioridades. A política estadual de resíduos sólidos não apareceu como prioridade em nenhuma LDO do período.
} 
indispensável, mas que muitas vezes não ganha tanta importância na concepção e análise de uma política pública, que são os recursos financeiros. Na administração pública brasileira eles estão presentes no sistema de planejamento e orçamento.

Em um estudo sobre cenários para o desenvolvimento no Brasil, o Ipea (2017) elegeu o planejamento eficaz como variável de impulso desse processo e dentre as principais legislações sobre o tema, o instituto destaca a implementação dos planos plurianuais (PPA) e a Lei de Diretrizes Orçamentárias (LDO) pela Constituição de 1988. Mas segundo o estudo, esses instrumentos tornaram os interesses do país muito subordinados ao planejamento de curto prazo, quadriênios, além disso, tornaram o planejamento muito burocrático, limitado às normas e com fraca articulação entre os entes federados. O estudo do Ipea (2017) apresenta também o argumento sobre a necessidade de instrumentos de planejamento de longo prazo, como a proposta de Emenda Constitucional (PEC) $n^{\circ}$ 122/2015 do Senado Federal, que institui os planos nacionais de desenvolvimento econômico e social, pluriquadrienal, como mecanismo orientador das propostas orçamentárias. Enquanto propostas como essa não mudam o processo de planejamento dos níveis de governo no Brasil, se faz necessário compreender através desses instrumentos, como as políticas públicas são executadas e quais os princípios que norteiam a prestação dos serviços públicos no país.

A Constituição de 1988 em seus princípios fundamentais postula que o Brasil é uma República Federativa formada pela união dos Estados e Municípios e do Distrito Federal, organizados de forma autônoma política e administrativamente (BRASIL, [2019]). Nessa perspectiva, o federalismo é um elemento essencial para análise de políticas de âmbito nacional que necessitem de coordenação, articulação e cooperação política e fiscal. Em relação ao aspecto fiscal, "o acompanhamento da execução orçamentária traz informações, entre outras, sobre a efetiva alocação de recursos às diversas políticas públicas e sua forma de financiamento, figurando entre os passos indispensáveis para a construção de um sistema de avaliação de políticas públicas" (GARSON, 2018, p. 56). Para a autora, a fase de execução orçamentária é determinante para a execução de uma dada política pública, uma vez que o excesso de gastos em uma área pode ocasionar prejuízo em outra política pública. Em relação ao orçamento, a Constituição estabelece que as diretrizes, metas, prioridades da administração pública federal, e por mandado constitucional, estadual, municipal e distrital, deverão estar contidos nas seguintes leis: 1) Plano Plurianual; 2) Diretrizes Orçamentárias e 3) Orçamentos Anuais, compondo assim o Sistema de Planejamento e Orçamento brasileiro.

Em relação ao Plano Plurianual (PPA), Albuquerque, Medeiros e Feijó (2008) comparam o instrumento a um "plano de voo", no qual são estabelecidas as ações necessárias para se chegar ao "destino" em um período de quatro anos, conceitualmente, é definido pelos autores como instrumento legal de planejamento de maior alcance temporal no estabelecimento das prioridades e no direcionamento das ações do governo. Para a sua formulação é estimulado o planejamento 
estratégico para que não seja apenas um plano operacional, mas sim, um instrumento que se busca o desenvolvimento do Estado. Para isso, de acordo Garson (2018) no PPA devem estar contidas as despesas de capital e que seja considerada a demanda adicional de gastos correntes necessários ao funcionamento e manutenção do crescimento do patrimônio público, ou seja, as despesas que decorrem do aumento de capital. Além disso, também devem ser levadas em consideração as despesas dos programas de duração continuada, que compreendem os gastos com a prestação de serviços públicos permanentes, com origem em gestões anteriores e que permanecem ao longo do tempo, como por exemplo, a despesa com pessoal. Apesar de não existir um modelo para elaboração do PPA no país, o modelo desenvolvido pela União vem sendo utilizado como modelo pelos estados e municípios.

Já a Lei de Diretrizes Orçamentárias (LDO) é responsável por fazer a ponte entre o PPA e a Lei Orçamentária Anual (LOA), estabelecendo dentre os "programas" utilizados no PPA, quais terão prioridade na execução do orçamento, além de disciplinar a elaboração e execução dos orçamentos (ALBUQUERQUE; MEDEIROS; FEIJÓ, 2008). A Constituição de 1988 (BRASIL, [2019]), §2 do art. 165, define que a LDO deve apresentar as metas e prioridades, orientar a elaboração da LOA, informar alterações na legislação tributária e estabelecer políticas relacionadas às agências financeiras oficiais de governo. Segundo Garson (2018), além disso, a Lei de Responsabilidade Fiscal (LRF) informa que a LDO deverá dispor sobre as normas de controle de custos e avaliação de resultados dos Programas. Para a autora, a LDO operacionaliza o PPA, conferindo ao Poder Legislativo maior participação no processo orçamentário e controle das finanças públicas, após duas décadas de governos autoritários.

Já a continuidade da operacionalização do PPA é dada através da LOA, que de acordo com a Constituição de 1988 (BRASIL, [2019]), deverá ser composta por três orçamentos: a) Orçamento fiscal; b) Orçamento de investimento das empresas públicas; c) Orçamento da seguridade social. A integração do PPA, planejamento de médio prazo, com os orçamentos anuais, representado pela LOA, acontece através da transformação dos "Programas" em "Ações", é dessa forma que os recursos são distribuídos nas LOAs. Essas "Ações" consolidam-se na LOA em "Programas de Trabalho" e a identificação dos "Programas" e "Ações" do PPA na LOA é dada através das “Classificações Orçamentárias”. Com as classificações orçamentárias é possível fazer avaliações da política fiscal e das finanças públicas em comparação com outros países, que são utilizadas no PPA, na LOA, no Balanço e outros demonstrativos da execução orçamentária (GARSON, 2018).

Desse modo, é através desses três instrumentos de planejamento e orçamento que a administração pública em seus níveis no Brasil apresenta como as políticas públicas serão executadas, quais os montantes de recursos definidos e como serão aplicados pelos governos. No país, as responsabilidades administrativas e políticas são divididas para cada esfera de governo, como também, cada ente possui responsabilidades sobre as receitas, despesas e transferências. De 
acordo com Lima (2015), são esses os aspectos políticos e fiscais do federalismo. Esses princípios buscam uma melhor distribuição dos gastos públicos dentro das federações, uma vez que a descentralização aumentaria o controle da população. No entanto, em algumas situações, a provisão de serviços pelo governo central produz ganhos de escala, com um dado padrão de qualidade para todo o território nacional, caracterizando assim um trade-off entre centralização e descentralização. Na prática, esse dilema é administrado através do princípio da subsidiariedade, bens e serviços mais próximos da população e menos complexos ficam a cargo dos governos locais. No caso brasileiro, os municípios, por exemplo, ficaram responsáveis por serviços como: saúde e educação básica, limpeza urbana, coleta e gestão de resíduos, etc. Já os gastos que apresentam significativas externalidades entre as unidades da federação ficaram com as esferas mais altas, evitando assim a sobrecarga de um ente, como, por exemplo, a construção e manutenção de hospitais de referências na saúde e as universidades na educação. Esses serviços são consumidos por moradores de diversos municípios sendo mais recomendado que os governos estaduais e central assumam a responsabilidade de gastos.

Dessa forma, o que se conclui é que a análise da implementação de uma política pública através da execução orçamentária e financeira pode revelar de que forma políticas de cunho nacional, como a Política Nacional de Resíduos Sólidos, são executadas em seus aspectos temporais, espaciais e estratégicos, revelando a maneira que ocorre a articulação entre os entes federados. É diante desse aporte teórico que o estudo buscar a analisar a política estadual de resíduos sólidos no estado de Alagoas.

\section{Panorama da Política Nacional de Resíduos Sólidos}

Faz quase uma década que a PNRS está em vigor no país, apesar disso, ainda cerca de $48 \%{ }^{2}$ dos municípios brasileiros utilizavam lixões como disposição final de resíduos sólidos (CONFEDERAÇÃO NACIONAL DE MUNICÍPIOS, 2017). A PNRS colocou o horizonte de quatro anos para que todos os municípios tenham dado destinação ambientalmente adequada aos rejeitos produzidos localmente, porém vinculou a elaboração do Plano Municipal de Gerenciamento Integrado de Resíduos Sólidos (PMGIRS) à liberação de recursos federais (NASCIMENTO et al., 2015). Como muitos municípios não apresentaram seus Planos, ficaram sem recursos para gerenciamento dos resíduos sólidos, o que explica parcialmente a situação precária da destinação final do lixo, apesar da legislação em vigor. Esse fato demonstra a importância de obter recursos orçamentários e de planejar sua execução para estar em conformidade com a lei.

\footnotetext{
${ }^{2}$ A pesquisa foi feita por manifestação espontânea. Foram consultados 5.568 municípios brasileiros, desse total, 4.224 municípios $(75,6 \%)$ responderam a pesquisa $(\mathrm{CNM}, 2017)$.
} 
O objetivo da política nacional é destinar os resíduos sólidos em aterros, sujeitos à normas operacionais específicas, evitando assim danos à saúde humana e ao meio ambiente. Contudo, a política enfrenta problemas para sua efetivação, como a baixa disponibilidade orçamentária, pessoal sem qualificação, equipamentos danificados e obsoletos e a fraca capacidade institucional de diversos municípios, nos quais a lógica competitiva prevalece sobre os fins cooperativos (MARCHI, 2015; MAIELLO; BRITTO; VALLE, 2018). Além disso, em relação à geração desses resíduos, não existe no Brasil uma perspectiva de diminuição de sua quantidade per capita, aumentando a cada ano (NASCIMENTO et al., 2015), agravando ainda mais a situação de municípios que não possuem um PMGIRS.

Para superar esses desafios, a PNRS disponibilizou instrumentos importantes para o adequado manejo dos resíduos sólidos, com impactos significativos nos problemas ambientais, sociais e econômicos gerados pelos lixões (BRASIL, 2017). Além disso, o compartilhamento de responsabilidades, materializada pela necessidade de elaboração dos planos de gerenciamento de resíduos sólidos, é o grande destaque para cumprimento das metas do plano que visa:

1. Redução dos resíduos sólidos urbanos (RSU) úmidos;

2. Redução da geração de RSU;

3. Disposição final ambientalmente adequada;

i. Eliminar os lixões e aterros controlados;

ii. Recuperar os lixões e aterros controlados;

iii. Desenvolver tecnologias para reduzir a disposição final em aterros sanitários;

iv. Criar o índice nacional de qualidade dos aterros sanitários;

4. Redução dos RSU secos em aterros sanitários e inclusão de catadores.

Em Brasil (2017), buscou-se avaliar a PNRS em relação à meta 3.i. (Eliminar os lixões e aterros controlados) com ênfase na participação da União (Ministério do Meio Ambiente, Ministério das Cidades e Fundação Nacional de Saúde - Funasa) no processo de elaboração dos planos estaduais e municipais. Em relação aos primeiros, de acordo com a Confederação Nacional dos Municípios (CONFEDERAÇÃO NACIONAL DE MUNICÍPIOS, 2019), 14 estados haviam finalizado o plano estadual de resíduos sólidos (AC, AL, AM, CE, GO, MA, PA, PE, RJ, RS, SC, SE, SP, TO), oito estados não tinham finalizado (AP, BA, ES, MG, MT, MS, PB, RO), quatro não haviam iniciado (PI, PR, RN, RR) e o Distrito Federal não deve elaborar o referido plano. Em relação aos Planos Municipais de Gestão Integrada de Resíduos Sólidos (PGIRS), em 2017, $38,2 \%$ dos municípios haviam finalizado o plano, $38,7 \%$ estavam elaborando, 20,4\% não haviam iniciado e 2,7\% não souberam ou não responderam (CNM, 2017).

Em relação à situação da gestão dos resíduos sólidos municipais, a Tabela 1 apresenta o diagnóstico no final de 2017. 
Tabela 1 - Diagnóstico da Política Nacional de Resíduos Sólidos nos municípios em 2017

\begin{tabular}{lcccccc}
\hline \multirow{2}{*}{ ANO } & \multicolumn{5}{c}{ Diagnóstico da gestão municipal de resíduos sólidos no Brasil } \\
\cline { 2 - 6 } & $\begin{array}{c}\text { Lixão/ } \\
\text { aterro } \\
\text { controlado }\end{array}$ & $\begin{array}{c}\text { Aterro } \\
\text { sanitário }\end{array}$ & $\begin{array}{c}\text { PGIRS } \\
\text { finalizado }\end{array}$ & $\begin{array}{c}\text { Coleta } \\
\text { seletiva }\end{array}$ & Compostagem & $\begin{array}{c}\text { Consórcios } \\
\text { de resíduos } \\
\text { sólidos }\end{array}$ \\
\hline 2017 & $48,0 \%$ & $47,5 \%$ & $38,2 \%$ & $48,3 \%$ & $12,2 \%$ & $29,5 \%$ \\
\hline
\end{tabular}

Fonte: CNM (2017).

Na tabela 1 é possível constatar que $48 \%$ dos municípios analisados ainda destinam seus resíduos sólidos em lixões ou aterros controlados. Além disso, menos de $40 \%$ das prefeituras possuem o PGIRS concluído, o que impede o acesso aos recursos da União para implementação das ações voltadas à gestão dos resíduos sólidos. A ausência do planejamento se reflete também nos indicadores dos serviços de coleta seletiva presente em $48 \%$ dos municípios e compostagem em apenas 12,2\%. Em relação aos consórcios, a ferramenta é fundamental para a escala da gestão dos resíduos sólidos, uma vez que reduz os custos de disposição final nos aterros sanitários, mas para isso é fundamental o apoio da gestão pública em sua constituição. De acordo com CNM (2017), a grande maioria dos consórcios ativos no país ainda busca por recursos para construção de seus aterros sanitários

O relatório de auditoria (BRASIL, 2017) ainda aponta que apesar da Lei $n^{\circ} 12305 / 2010$ está em vigor, a União ainda não publicou o Plano Nacional de Resíduos Sólidos. Concluído em 2012, o plano já deveria ter sido atualizado, uma vez que a PNRS determina sua revisão a cada quatro anos. Mesmo assim, o plano vem sendo utilizado pela União, de forma não plenamente válida e desatualizada, assim, o governo federal não possui um instrumento legítimo para servir de orientação aos estados e municípios no processo de elaboração de seus planos (BRASIL, 2017, p. 10). Contudo, o cenário é positivo, pois com a PNRS, a União tem estruturado ações de apoio e incentivo à gestão adequada dos resíduos sólidos no país com uma maior participação dos estados na transferência de recursos para os municípios, destacando-se as ações consorciadas (MANNARINO; FERREIRA; GANDOLLA, 2016). Em Alagoas, a regionalização da política estadual permitiu a construção de 07 consórcios e construção de mais três Centrais de Tratamentos de Resíduos para por fim na destinação de resíduos sólidos em lixões.

\section{Política estadual de resíduos sólidos em Alagoas}

A Lei n 7749 de 13 de outubro de 2015 instituiu a PERS em Alagoas com seus objetivos, princípios, instrumentos e foco na gestão integrada e gerenciamento dos resíduos sólidos, alinhados com as políticas estaduais de meio ambiente, recursos hídricos, saneamento básico e promoção da inclusão social. Dentre os instrumentos previstos para atingir os objetivos da política os principais são:

- Plano Estadual de Resíduos Sólidos;

- Planos de Gestão Integrada de Resíduos Sólidos Municipais e Intermunicipais; 
- Planos de Gerenciamento de Resíduos Sólidos;

- Sistema de Informação de Resíduos Sólidos Estadual;

- Cooperação técnica e financeira;

- Programa Alagoas Catador;

- Estruturação de sistema de coleta seletiva e de logística reversa.

De acordo com a Floram Engenharia e Meio Ambiente (2016), antes mesmo da política ser instituída, três planos foram elaborados pelo estado de Alagoas:

1. Plano estadual de regionalização dos resíduos sólidos do estado de Alagoas

Esse plano foi elaborado em 2010 e teve como principal objetivo criar regiões para compartilhamento da gestão dos resíduos sólidos urbanos, tendo como critérios: facilidade logística, desenvolvimento regional, e tipologia dos resíduos. Dessa forma, sete regiões foram definidas para planejamento e criação dos consórcios públicos no estado de Alagoas.

2. Plano de gestão integrada de resíduos sólidos dos municípios alagoanos inseridos na bacia do rio São Francisco

O plano, elaborado em 2011, contemplou a gestão integrada dos resíduos sólidos na bacia do rio São Francisco divididos em quatro regiões: Sertão, Bacia Leiteira, Agreste e Sul, no qual foi feito um diagnóstico preliminar dos resíduos sólidos na região, através de arranjos que levassem em consideração projeção de cenários econômicos e gestão integrada.

3. Plano Estadual de Resíduos Sólidos de Alagoas

O plano já vinha sendo discutido antes da política ser instituída em 2015 e capacitações com técnicos advindos dos municípios em cada região do plano de regionalização foram realizadas em 2014.

Assim, considerando os aspectos socioeconômicos e ambientais do estado de Alagoas, as sete regiões (figura 1) de gestão de resíduos sólidos foram definidas em:

1. Região do Agreste Alagoano - Arapiraca, Traipu, Girau do Ponciano, Lagoa da Canoa, Feira Grande, Campo Grande, São Sebastião, Limoeiro de Anadia, Craíbas, Igaci, Coité do Nóia, Taquarana, Maribondo, Belém, Tanque d'Arca, Palmeira dos Índios, Olho d' Água Grande, Minador do Negrão, Quebrangulo e Estrela de Alagoas;

2. Região da Bacia Leiteira - Olho d'Água das Flores, Santana do Ipanema, Ouro Branco, Maravilha, Poço das Trincheiras, Senador Rui Palmeira, Carneiros, São José da Tapera, Pão de Açúcar, Belo Monte, Palestina, Jacaré dos Homens, Monteirópolis, Olivença, Major Isidoro, Dois Riachos, Cacimbinhas, Jaramataia e Batalha; 
3. Região do Litoral Norte de Alagoas - Maragogi, Japaratinga, Porto de Pedra, São Miguel dos Milagres, Passo de Camaragibe, São Luiz do Quitunde, Flexeiras, Joaquim Gomes, Matriz de Camaragibe, Porto Calvo, Jundiá, Novo Lino, Colônia Leopoldina, Campestre e Jacuípe;

4. Região Metropolitana Alagoana - Rio Largo, Messias, Barra de Santo Antônio, Coqueiro Seco, Satuba, Santa Luzia do Norte, Pilar, Paripueira, Marechal Deodoro e Maceió;

5. Região do Sertão Alagoano - Delmiro Gouveia, Pariconha, Água Branca, Mata Grande, Canapi, Inhapi, Olho d’Água do Casado e Piranhas;

6. Região Sul do Estado de Alagoas - Coruripe, Jequiá da Praia, Anadia, Boca da Mata, Campo Alegre, São Miguel dos Campos, Roteiro, Piaçabuçu, Igreja Nova, Porto Real do Colégio, Teotônio Vilela, Barra de São Miguel, Feliz Deserto, Penedo e mais (02) dois Municípios que migraram da Região Agreste (Junqueiro e São Brás);

7. Região da Zona da Mata Alagoana - União dos Palmares, Ibateguara, São José da Laje, Santana do Mundaú, Branquinha, Murici, Capela, Cajueiro, Atalaia, Pindoba, Mar Vermelho, Paulo Jacinto, Viçosa, Chã Preta.

Figura 1 - Microrregiões de gestão dos resíduos sólidos no estado de Alagoas.

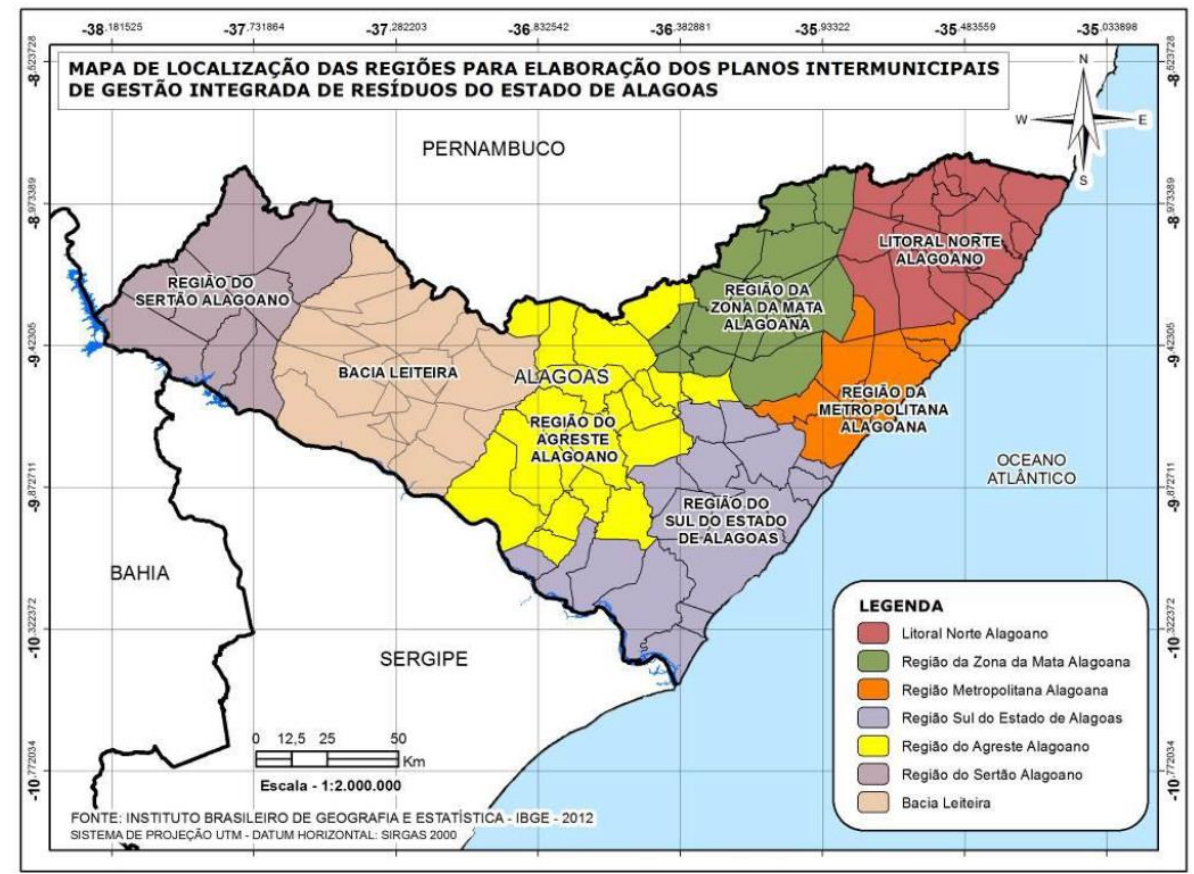

Fonte: Floram Engenharia e Meio Ambiente (2016) adaptado de SEMARH/AL (2010).

A divisão do estado em regiões visando à gestão integrada dos resíduos sólidos é fundamental, pois possibilita a proposição de sistemas de tratamentos de resíduos sólidos com redução de custos de gestão e gerenciamento, diminuindo os passivos ambientais. Assim, foram constituídos sete consórcios públicos, que à época de elaboração do plano estadual, estavam em fase de estruturação (FLORAM ENGENHARIA E MEIO AMBIENTE, 2016). O quadro 1 
apresenta os consórcios constituídos com data de criação e central de tratamento de resíduos (CTR) utilizada por cada um.

Quadro 1 - Consórcios regionais e centrais de tratamento de resíduos sólidos em Alagoas

\begin{tabular}{|c|c|c|c|}
\hline $\begin{array}{c}\text { Região/ } \\
\text { Município }\end{array}$ & Consórcio & $\begin{array}{l}\text { Ano de } \\
\text { criação }\end{array}$ & $\begin{array}{c}\text { Central de } \\
\text { Tratamento de } \\
\text { Resíduo (CTR) }\end{array}$ \\
\hline Agreste & $\begin{array}{l}\text { CONAGRESTE - Consórcio Regional } \\
\text { de Resíduos Sólidos do Agreste } \\
\text { Alagoano }\end{array}$ & 2013 & CTR Agreste \\
\hline Bacia Leiteira & $\begin{array}{l}\text { CIGRES - Consórcio Intermunicipal } \\
\text { para Gestão dos Resíduos Sólidos }\end{array}$ & 2006 & $\begin{array}{l}\text { Aterro CIGRES - Olho } \\
\text { D’Água das Flores }\end{array}$ \\
\hline Litoral Norte* & $\begin{array}{l}\text { CONORTE - Consórcio Intermunicipal } \\
\text { de Desenvolvimento da Região Norte de } \\
\text { Alagoas }\end{array}$ & 2011 & CTR Metropolitana \\
\hline Metropolitana** & $\begin{array}{l}\text { Consórcio Regional Metropolitano de } \\
\text { Resíduos Sólidos de Alagoas }\end{array}$ & 2011 & CTR Metropolitana \\
\hline Sertão & $\begin{array}{l}\text { CRERSSAL - Consórcio Regional de } \\
\text { Resíduos Sólidos do Sertão de Alagoas }\end{array}$ & 2013 & $\begin{array}{l}\text { Aterro CIGRES - Olho } \\
\text { D’Água das Flores }\end{array}$ \\
\hline Sul*** & $\begin{array}{l}\text { CONISUL - Consórcio Intermunicipal } \\
\text { do Sul do Estado de Alagoas }\end{array}$ & 2013 & CTR Agreste \\
\hline Zona da Mata & $\begin{array}{l}\text { CORSZAM - Consórcio Regional de } \\
\text { Resíduos Sólidos da Zona da Mata } \\
\text { Alagoana }\end{array}$ & 2011 & CTR Metropolitana \\
\hline \multicolumn{4}{|c|}{ Observacão: } \\
\hline $\begin{array}{l}\text { *Maragogi } \\
\text { Japaratinga }\end{array}$ & - & - & $\begin{array}{l}\text { Aterro Consórcio Portal } \\
\text { Sul (Rio Formoso - PE) }\end{array}$ \\
\hline **Maceió & - & - & CTR de Maceió \\
\hline ***São Brás & - & - & $\begin{array}{l}\text { Aterro Ambiental } \\
\text { Rosário (SE) }\end{array}$ \\
\hline
\end{tabular}

Fonte: Floram Engenharia e Meio Ambiente (2016) e Alagoas (2018).

Após analisar as informações do Quadro 1 é possível perceber que apesar de existirem sete consórcios constituídos para cada região de gestão dos resíduos sólidos, existem somente três CTR para atender às sete regiões. Destinar os resíduos sólidos para outras regiões foi a alternativa encontrada pelos consórcios das regiões do Litoral Norte, Sertão e Sul do estado, para cumprir a meta de encerramento dos lixões. De acordo com o prefeito de Porto Calvo, região Litoral Norte, David Pedrosa (2017),

[...] a instalação da estação de transbordo ${ }^{3}$ foi a forma mais econômica de cumprir a lei, já que criar um aterro sanitário seria muito mais caro e teria um custo aproximado de $\mathrm{R} \$ 20$ milhões, além de levar cerca de três a quatro anos para funcionar, depois de cumprir todo o tramite burocrático para obter o licenciamento ambiental. (LUNA, 2017).

Além disso, quatro municípios não participam de nenhum dos consórcios criados, Maceió possui aterro sanitário desde 2010, Maragogi e Japaratinga - municípios do Litoral Norte destinam seus resíduos para a CTR de Rio Formoso em Pernambuco e a cidade de São Brás,

\footnotetext{
${ }^{3}$ A estação de transbordo é um local que serve para transferência dos resíduos coletados nos municípios consorciados para carretas que levam o lixo para a CTR de outra região.
} 
região Sul, destina seus resíduos sólidos para a CTR de Rosário do Catete em Sergipe (ALAGOAS, 2018a). Com efeito, o governo do estado de Alagoas conseguiu encerrar em 25 de maio de 2018 todos os lixões presentes nos municípios.

É importante destacar que o plano estadual disponibilizou cenários para cada região e consórcio, de acordo com as respectivas características socioeconômicas. Isso significa que cada CTR foi planejada para absorver a demanda dos municípios constituintes, ou seja, ao absorver a demanda de outras regiões, as três CTR (Aterro Cigres, Metropolitana e Agreste) em operação poderão ter sua vida útil prejudicada.

O plano também consolidou a estimativa de recursos para investimentos "em obras físicas, aquisição e instalação de equipamentos, custos operacionais e de gerenciamento do sistema além dos recursos a serem aplicados nos programas de mobilização política e social, e normatização das relações futuras entre os agentes envolvidos. " (FLORAM ENGENHARIA E MEIO AMBIENTE, 2016, p. 983). Os investimentos e custos estimados foram associados diretamente à implementação dos cinco programas propostos no plano estadual de resíduos sólidos (PERS). A Tabela 1 apresenta o custo anual.

Tabela 1 - Recursos financeiros necessários para implantação dos programas do PERS-AL (R\$ de 2018)

\begin{tabular}{ll}
\hline \multicolumn{1}{c}{ Projetos e ações } & Custo (R\$) \\
\hline $\begin{array}{ll}\text { 1. Programa de Desenvolvimento do Conhecimento e Capacitação em Resíduos } \\
\text { Sólidos }\end{array}$ & $385.669,00$ \\
\hline 2. Programa de Informatização da Gestão de Resíduos Sólidos & $503.825,80$ \\
\hline 3. Programa de Fiscalização Integrada e Regularização da Gestão Resíduos Sólidos & $27.010,50$ \\
\hline 4. Programa de Desenvolvimento Socioambiental para Resíduos Sólidos & $760.072,53$ \\
\hline 5. Programa de Estruturação da Gestão de Resíduos Sólidos & $3.034 .922,46$ \\
\hline Valor total Estimado Anual & $\mathbf{4 . 7 1 1 . 5 0 1 , 5 4}$ \\
\hline
\end{tabular}
Fonte: Floram Engenharia e Meio Ambiente (2016).

O custo anual estimado, em reais de 2018 , foi de aproximadamente $\mathrm{R} \$ 4,71$ milhões, por ano de execução e por um período de quatro anos, totalizando $\mathrm{R} \$ 18,85$ milhões. Nessa perspectiva, com a formação dos sete consórcios, a elaboração do PERS e dos Planos Intermunicipais de Gestão dos Resíduos Sólidos (PIGIRS) o estado de Alagoas obteve acesso aos recursos da União para implementação das ações voltadas a gestão dos resíduos sólidos no estado.

\section{Análise da execução orçamentária e financeira do PERS de Alagoas}

Em termos de planejamento e orçamento, a política estadual de resíduos sólidos vem sendo desenvolvida a partir do Plano Plurianual (PPA) 2008-2011 do estado de Alagoas, com o Programa "Revitalização do Rio São Francisco" e Ação "Diagnóstico Ambiental dos Resíduos Sólidos", Tabela 2, que tinha como finalidade desenvolver a política estadual de resíduos sólidos. 
A Ação tinha como Meta o diagnóstico ambiental realizado em cada região do estado: Agreste, Norte, Sul, Metropolitana de Maceió, Sertão, Bacia Leiteira e Vales do Paraíba e do Mundaú.

Tabela 2 - Ação da política estadual de resíduos sólidos e respectivo orçamento do PPA 2008-2011 do estado de Alagoas, valores constantes (reais de 2018)

\begin{tabular}{ll}
\hline Programa: Revitalização do Rio São Francisco & \\
\cline { 1 - 2 } Ação: Diagnóstico Ambiental de Resíduos Sólidos & 4.010 .573 \\
\hline Finalidade: Desenvolver a política estadual de resíduos sólidos & \\
\hline Recursos Ordinários $^{4}$ & 601.586 \\
\hline Despesas correntes $^{5}$ & 0 \\
\hline Despesas de capital & 3.408 .986 \\
\hline Convênios & 0 \\
\hline Despesas correntes & \\
\hline Despesas de capital &
\end{tabular}

Fonte: Alagoas (2008).

Na Tabela 2 é possível perceber que grande parte dos recursos destinados à Ação, cerca de 4 milhões de reais, advinham de "convênios", como também alocados em despesas correntes. Ao analisar as Leis Orçamentárias Anuais (LOA) do período 2008-2011 e seus respectivos balanços identifica-se como essa Ação/Projeto foi executada, a Tabela 3 reúne as informações.

Tabela 3 - Recursos alocados e apuração dos gastos nas Ações e Projetos em torno da política de resíduos sólidos em Alagoas, segundo LOAs e Balanços entre 2008 e 2011, em valores constantes (reais de 2018)

\begin{tabular}{|c|c|c|c|c|}
\hline \multirow{4}{*}{$\begin{array}{l}\text { Ação/Projeto } \\
\begin{array}{l}\text { Diagnóstico ambiental de resíduos } \\
\text { sólidos. }\end{array}\end{array}$} & \multirow{3}{*}{\begin{tabular}{|l|} 
ANO \\
2008
\end{tabular}} & \multirow{2}{*}{$\begin{array}{c}\text { LOA } \\
(\mathbf{R} \$)\end{array}$} & \multicolumn{2}{|c|}{ Balanço } \\
\hline & & & \multirow{2}{*}{$\begin{array}{l}\text { Ordinário } \\
359,29\end{array}$} & \multirow{2}{*}{$\begin{array}{ll} & \text { Vinculado } \\
0 & \end{array}$} \\
\hline & & $117.584,25$ & & \\
\hline & 2009 & $615.624,92$ & $6.133,69$ & $38.894,61$ \\
\hline \multicolumn{2}{|l|}{ Total $(2008+2009)$} & 733.209,16 & $6.492,98$ & 38.894,61 \\
\hline \multirow{2}{*}{$\begin{array}{llll}\begin{array}{l}\text { Elaboração } \\
\text { regionalização }\end{array} & \text { da } & \text { plano } & \text { de } \\
\text { gestão } & \text { de } \\
\text { resíduos sólidos. } & & \\
\end{array}$} & 2010 & $1.149 .246,25$ & $55.284,07$ & $235.276,53$ \\
\hline & 2011 & 1.038.387,91 & $20.001,39$ & $164.497,50$ \\
\hline \multicolumn{2}{|l|}{ Total $(2010+2011)$} & 2.187.634,16 & $75.285,45$ & 399.774,03 \\
\hline \multirow[t]{2}{*}{ Total (2008 a 2011) } & & $2.920 .843,33$ & $81.778,43$ & $438.668,64$ \\
\hline & & & \multicolumn{2}{|c|}{$520.447,06$} \\
\hline \multicolumn{3}{|l|}{ LOAs menos Balanços 2008 a 2011} & \multicolumn{2}{|l|}{$2.400 .396,26$} \\
\hline
\end{tabular}

Fonte: Alagoas (2008;2009;2010;2011).

Em 2008 e 2009 foi planejada a Ação "Diagnóstico ambiental de resíduos sólidos” e nas LOAs de 2010 e 2011 a Ação se tornou um Projeto com objetivo de elaborar o plano de regionalização da gestão de resíduos sólidos e estava inserido no Programa de "Revitalização de Bacias Hidrográficas". O orçamento inicial previsto para a Ação e Projeto em torno da política estadual de resíduos sólidos foi de aproximadamente 4 milhões de reais. Após análise das LOAs

\footnotetext{
${ }^{4}$ Os recursos ordinários são recursos de impostos e transferências sem vinculação do recurso no momento da arrecadação da receita. Já os recursos vinculados. Fonte: http://www.tesouro.fazenda.gov.br/ Acesso: 22 jul. 2019. ${ }^{5}$ As despesas correntes estão relacionadas à manutenção dos serviços públicos durante o exercício fiscal, enquanto que as despesas de capital são os investimentos realizados, podendo ou não entrar em operação no ano da despesa (GARSON, 2018).
} 
2008, 2009, 2010 e 2011 foram executados cerca de quinhentos e vinte mil reais, representando cerca de $17,80 \%$ do que foi planejado para o período. Desse volume de recursos executados, cerca de 84\%, 438 mil reais, tiveram como fonte recursos vinculados, ou seja, recursos que não são de fonte própria do estado de Alagoas. É importante também destacar a diferença entre o que foi planejado em termos de recursos no PPA 2008-2011, 4 milhões de reais (tabela 3), os valores planejados nas LOAs, cerca de 3 milhões e o que foi de fato executado, 520 mil reais (tabela 4 ).

Já no PPA 2012/2015 a política entrou como Ação em três Programas: "Gestão integrada do meio ambiente e recursos hídricos"; "Administração Financeira" e "Produtividade e valor agregado da agricultura familiar, pecuária, aquicultura e da cadeia produtiva do leite", ver tabela 4.

Tabela 4 - Ações da política estadual de resíduos sólidos e respectivos orçamentos do PPA 20122015 do estado de Alagoas, valores constantes (reais de 2018). Programa: Gestão integrada do meio ambiente e recursos hídricos $384.912,17$

Ação: Implementação da política estadual de resíduos sólidos

Finalidade: Desenvolver a política de resíduos sólidos no estado

Recursos Ordinários

Despesas correntes

Programa: Administração Financeira

Ação: Implantação de sistema integrado de gerenciamento de resíduos sólidos

Finalidade: Prover de infraestrutura básica, os sistemas públicos de gerenciamento de resíduos sólidos, através da elaboração de Estudos e projetos, para a implantação de aterros sanitários.

Recursos Ordinários

Despesas de capital

Compensação financeira xisto betuminoso e gás

Despesas de capital

Cota-parte xisto betuminoso e gás

Despesas de capital

Convênios

Programa: Produtividade e valor agrega

Ação: Construção de posto de recolhimento de embalagens vazias de agrotóxicos e afins

Finalidade: Desenvolvimento de ações para a diminuição dos resíduos agrotóxicos nos alimentos comercializados, a redução dos danos ambientais que venham causar acidentes e problemas de saúde na população

Recursos Ordinários

Despesas correntes

Despesas de capital

Recursos da Administração Indireta

Despesas correntes

Fonte: Alagoas (2012).

No PPA 2012-2015 foram alocados cerca de 2 milhões de reais, $\mathrm{R} \$ 1.901 .649,81$, as três Ações visavam desenvolver a política e implantar o sistema integrado de gerenciamento de resíduos sólidos, além de construir um posto de recolhimento de resíduos agrotóxicos no estado de Alagoas. Os recursos foram alocados em despesas correntes e de capital. 
Nas LOAs do período 2012 - 2015 as Ações foram inseridas como Projetos, a tabela 5 apresenta a alocação dos recursos anuais e a respectiva apuração do gasto através dos Balanços.

Tabela 5 - Recursos alocados e apuração dos gastos nos Projetos em torno da política de resíduos sólidos em Alagoas, segundo LOAs e Balanços entre 2012 e 2015, em valores constantes (reais de 2018).

\begin{tabular}{|c|c|c|c|c|c|}
\hline \multirow{2}{*}{ Projeto } & \multirow{2}{*}{ ANO } & \multicolumn{2}{|c|}{ LOA } & \multicolumn{2}{|c|}{ Balanço } \\
\hline & & Corrente & Capital & Ordinário & Vinculado \\
\hline $\begin{array}{l}\text { Implantação de sistema integrado } \\
\text { de gerenciamento de resíduos } \\
\text { sólidos. }\end{array}$ & & 0 & $223.217,06$ & 0 & 0 \\
\hline $\begin{array}{l}\text { Implementação da política estadual } \\
\text { de resíduos sólidos }\end{array}$ & 2012 & $29.962,02$ & 0 & $16.166,67$ & 0 \\
\hline $\begin{array}{l}\text { Construção de posto de } \\
\text { recolhimento de embalagens vazias } \\
\text { de agrotóxicos e afins }\end{array}$ & & $265.649,28$ & $265.649,28$ & $105.935,81$ & $163.969,17$ \\
\hline Total & & 295.611,30 & $488.866,34$ & $122.102,47$ & $163.969,17$ \\
\hline $\begin{array}{l}\text { Implantação de sistema integrado } \\
\text { de gerenciamento de resíduos } \\
\text { sólidos. }\end{array}$ & & $7.077,87$ & $\begin{array}{l}1.423 .572 \\
57\end{array}$ & 0 & 0 \\
\hline $\begin{array}{l}\text { Implementação da política estadual } \\
\text { de resíduos sólidos }\end{array}$ & 2013 & $\begin{array}{l}1.561 .276 \\
69\end{array}$ & 0 & $180.329,07$ & $\begin{array}{l}1.236 .931, \\
33\end{array}$ \\
\hline Total & & $\begin{array}{l}1.568 .354 \\
56\end{array}$ & $\begin{array}{l}\text { 1.423.572, } \\
57\end{array}$ & $180.329,07$ & $\begin{array}{l}\text { 1.236.931, } \\
33\end{array}$ \\
\hline $\begin{array}{l}\text { Implantação de sistema integrado } \\
\text { de gerenciamento de resíduos } \\
\text { sólidos. }\end{array}$ & & 0 & $\begin{array}{l}3.970 .958 \\
73\end{array}$ & 0 & 0 \\
\hline $\begin{array}{l}\text { Implementação da política estadual } \\
\text { de resíduos sólidos }\end{array}$ & 2014 & $\begin{array}{l}5.896 .996 \\
32\end{array}$ & 0 & $8.494,67$ & $423.592,61$ \\
\hline Total & & $\begin{array}{l}5.896 .996 \\
32\end{array}$ & $\begin{array}{l}3.970 .958 \\
73\end{array}$ & $8.494,67$ & $423.592,61$ \\
\hline $\begin{array}{l}\text { Implantação de sistema integrado } \\
\text { de gerenciamento de resíduos } \\
\text { sólidos. }\end{array}$ & & 0 & $\begin{array}{l}1.758 .659 \\
49\end{array}$ & 0 & 0 \\
\hline $\begin{array}{l}\text { Implementação da política estadual } \\
\text { de resíduos sólidos }\end{array}$ & 2015 & $\begin{array}{l}5.485 .569 \\
24\end{array}$ & 0 & $185.076,16$ & $\begin{array}{l}2.773 .541 \\
98\end{array}$ \\
\hline Total & & $\begin{array}{l}5.485 .569 \\
24\end{array}$ & $\begin{array}{l}1.758 .659 \\
49\end{array}$ & $185.076,16$ & $\begin{array}{l}2.773 .541, \\
98\end{array}$ \\
\hline Total LOAs e Balanços 2012/2015 & & $\begin{array}{l}13.246 .531 \\
, 41\end{array}$ & $\begin{array}{l}7.642 .057 \\
13\end{array}$ & 496.002,38 & $\begin{array}{l}\text { 4.598.035, } \\
08\end{array}$ \\
\hline & & 20.888 & 588,54 & 5.094 & 33,46 \\
\hline LOAs - Balanços 2012/2015 & & & 15.79 & 551,08 & \\
\hline
\end{tabular}

Fonte: Alagoas (2012;2013;2014;2015;2016).

Entre 2012 e 2015, segundo as LOAs, a dotação orçamentária para a política estadual de resíduos sólidos no estado de Alagoas foi de cerca de 21 milhões de reais. Desse total, cerca de 1/4, 5 milhões de reais, foram gastos na política efetivamente, sendo que $90 \%$ desses recursos tiveram como fonte recursos vinculados, provavelmente da União, já que o governo do estado conseguiu elaborar seu plano estadual em 2015, requisito para ter acesso aos recursos do governo federal e de instituições financeiras públicas destinados à política de resíduos sólidos. Não por 
acaso, no ano de 2015 o governo do estado consegue ter acesso a cerca de 3 milhões de reais de recursos vinculados, o que representa 55\% do total gasto para o período $2012-2015$, ver tabela 5.

O último PPA analisado 2016-2019 contém mais uma Ação em torno da política estadual, nesse caso a Ação visa "Implantação da política estadual de resíduos sólidos" para o referido período, a tabela 6 apresenta as informações com as despesas correntes e de capital.

Tabela 6 - Ação de implantação da política estadual de resíduos sólidos e respectivos orçamentos do PPA 2016-2019 do estado de Alagoas, valores constantes (reais de 2018)

\begin{tabular}{ll}
\hline Programa: Recursos Hídricos e Meio Ambiente & $5.147 .847,57$ \\
\cline { 1 - 2 } $\begin{array}{l}\text { Ação: Implantação da política estadual de resíduos sólidos } \\
\text { Finalidade: Desenvolver a política de resíduos sólidos no estado, com o intuito } \\
\text { de implementar a política nos municípios alagoanos. }\end{array}$ \\
$\begin{array}{l}\text { Recursos Ordinários } \\
\text { Despesas correntes }\end{array}$ & $281.385,52$ \\
Despesas de capital & $30.148,45$ \\
Cota-parte xisto betuminoso e gás & $753.711,21$ \\
Despesas correntes & 0 \\
Despesas de capital & \\
Convênios & $4.082 .602,39$ \\
Despesas correntes & 0 \\
Despesas de capital &
\end{tabular}

Fonte: Alagoas (2015).

Esse PPA teve como dotação orçamentária cerca de 5 milhões de reais, novamente grande parte dos recursos tiveram como fonte recursos vinculados, como também, a maioria da previsão de gastos estavam alocados em despesas correntes. Já em relação à execução orçamentária e financeira, a análise das LOAs mostra uma dotação de cerca de 6,5 milhões de reais, concentrada em despesas correntes, e um gasto apurado até o ano de 2017 de pouco mais de 2 milhões de reais, tendo como fonte principal recursos vinculados, ver tabela 7.

Tabela 7 - Recursos alocados e apuração dos gastos da Ação "Implantação da política de resíduos sólidos em Alagoas, segundo LOAs e Balanços entre 2016 e 2018, em valores constantes (reais de 2018)

\begin{tabular}{|c|c|c|c|c|c|}
\hline \multirow[t]{2}{*}{ Ação } & \multirow[t]{2}{*}{ ANO } & \multicolumn{2}{|c|}{$\begin{array}{c}\text { LOA } \\
(\mathbf{R} \$)\end{array}$} & \multicolumn{2}{|c|}{ Balanço } \\
\hline & & Corrente & Capital & Ordinário & Vinculado \\
\hline \multirow{3}{*}{$\begin{array}{l}\text { Implantação da política estadual } \\
\text { de resíduos sólidos. }\end{array}$} & 2016 & $4.426 .784,92$ & $13.620,88$ & $54.583,89$ & $2.122 .285,04$ \\
\hline & 2017 & $2.189 .405,13$ & $8.544,02$ & $33.683,73$ & 0 \\
\hline & 2018 & $35.000,00$ & 0 & - & - \\
\hline \multirow{2}{*}{\multicolumn{2}{|c|}{ Total LOAs e Balanços* 2016/2018 }} & 6.651.190,05 & $22.164,90$ & $88.267,62$ & 2.122.285,04 \\
\hline & & \multicolumn{2}{|c|}{ 6.673.354,94 } & \multicolumn{2}{|c|}{$2.210 .552,66$} \\
\hline
\end{tabular}

Fonte: Alagoas (2015;2016;2017;2018). 
Assim, após a análise da execução orçamentária e financeira da política estadual de resíduos sólidos em Alagoas é possível identificar o volume total de recursos previsto alocado nos PPA 2008-2011; 2012-2015 e 2016-2015. Além disso, ao examinar as LOAs de 2008 a 2018, foi possível perceber como o planejamento em torno da política foi implementado anualmente, como também, identificar a dotação orçamentária. E por último, ao analisar os Balanços de cada ano no período, foi possível apurar o gasto efetivo da política ao longo desses 10 anos. A tabela 8 sintetiza as informações.

Tabela 8 - Execução orçamentária e financeira da política de resíduos sólidos em Alagoas, segundo PPA, LOAs e Balanços entre 2008 e 2018, em valores constantes (reais de 2018).

\begin{tabular}{llll}
\hline & \multicolumn{1}{c}{ PPA } & \multicolumn{1}{c}{ Total das LOAs } & \multicolumn{1}{c}{ Total dos Balanços } \\
\cline { 2 - 4 } Período & \multicolumn{3}{c}{ Valores em R\$ } \\
\hline $2008-2011$ & $4.010 .573,00$ & $2.920 .843,33$ & $520.447,06$ \\
\hline $2012-2015$ & $1.901 .649,81$ & $20.888 .588,54$ & $5.094 .037,46$ \\
& & & $2.210 .552,66$ \\
\hline $2016-$ & $5.147 .847,57$ & $6.673 .354,94$ & \\
$2019^{6}$ & & & $\mathbf{7 . 8 2 5 . 0 3 7 , 1 8}$ \\
\hline \multicolumn{2}{l}{ Total geral } & $\mathbf{1 1 . 0 6 0 . 0 7 0 , 3 8}$ & $\mathbf{3 0 . 4 8 2 . 7 8 6 , 8 1}$ \\
Fonte: elaborado pelo autor. & &
\end{tabular}

A análise dos três últimos PPA informa que o governo do estado de Alagoas planejou cerca de 11 milhões de reais para as ações e projetos que envolvem a política estadual de resíduos sólidos. Em relação à dotação orçamentária para o período, foram disponibilizados cerca de 30,5 milhões de reais em despesas correntes e de capital, grande parte concentrada na primeira despesa. Já em relação ao que de fato foi gasto na política no estado, o governo estadual gastou cerca de 8 milhões de reais em aproximadamente 10 anos, volume bastante inferior ao apresentado no plano estadual de resíduos sólidos, PERS, que previu um gasto necessário de aproximadamente 19 milhões em 4 anos para implementação dos cinco programas propostos, ver tabela 2. Contudo, é notável o aumento de gastos com o PPA 2012-2015, que conseguiu sair de um volume de 520 mil reais, no período anterior, para 5 milhões de reais e que aparentemente vem sendo mantido no período subsequente, com cerca de 2 milhões gastos até 2017.

\section{Considerações finais}

A política nacional de resíduos sólidos tem como seu marco legal a Lei n ${ }^{\circ}$ 12.305/2010 e quase uma década da sua instituição, o país ainda possui $48 \%$ dos seus municípios utilizando lixões à céu aberto, com graves prejuízos à saúde pública e ao meio ambiente. O estado de Alagoas consegue encerrar todos os lixões municipais em maio de 2018, apenas 03 anos depois da instituição da política estadual de resíduos sólidos, Lei $n^{\circ} 7749 / 2015$. Após análise dos instrumentos de planejamento e orçamento (PPA, LOA e Balanços) constatou-se que o governo

\footnotetext{
${ }^{6}$ Para o período 2016-2019, inclui somatório das LOAs até 2018 e no Balanço até o ano de 2017.
} 
estadual vem desde 2008 desenvolvendo ações em torno da política. Após análise do PPA 20082011 e das LOAs do período, foi possível identificar uma Ação e um Projeto que tinham como objetivo realizar o diagnóstico ambiental e elaborar o plano de regionalização da gestão de resíduos sólidos no estado, onde foram gastos cerca de 520 mil reais.

No entanto, é a partir do PPA 2012-2015 que as ações se intensificaram e a implantação da política ganha destaque nas LOAs do período e cerca de 5 milhões de reais foram gastos na implementação da política estadual de resíduos sólidos. Apesar de ter dotação orçamentária, a Ação "implantação de sistema integrado de gerenciamento de resíduos sólidos" não foi executada. No PPA subsequente, 2016-2019, o foco continua na implementação da política e até 2017 foram gastos cerca de 2 milhões de reais. Em dez anos de planejamento e execução orçamentária das ações para gerenciamento dos resíduos sólidos, mesmo quando a política estadual ainda não estava instituída em parte deste período, o governo do estado de Alagoas gastou cerca de $\mathrm{R} \$ 8$ milhões, contudo, só conseguiu realizar um terço dos gastos previstos nas dotações orçamentárias do período, o que provavelmente se reflete na operacionalização de somente três dos sete consórcios criados para destinação dos resíduos sólidos em Alagoas. Mesmo assim, o objetivo de eliminação dos lixões nos municípios alagoanos foi atingido com três Centrais de Tratamento de Resíduos Sólidos atendendo à demanda das sete regiões do estado.

Vale ressaltar que grande parte dos recursos efetivamente gastos são oriundos de recursos vinculados, ou seja, não foram provenientes do próprio estado. Esses recursos provavelmente vieram do governo federal, derivados da PNRS, que foram bem alocados pelo estado de Alagoas. Assim, a vinculação da liberação de recursos da União à apresentação dos Planos Municipais de Gerenciamento Integrado de Resíduos Sólidos foi um instrumento para forçar os municípios a buscarem soluções para o problema ambiental de disposição de seus resíduos. Isso evidencia a importância dos instrumentos de planejamento e orçamento na avaliação da efetividade da política de resíduos sólidos no Brasil.

Fica evidente, portanto, a importância de políticas públicas nacionais, que juntamente com políticas estaduais, acabam por ter um rebatimento positivo no bem-estar da população, contribuindo para diminuição das condições precárias de saneamento nos centros urbanos. Como muitos estados brasileiros ainda não conseguiram eliminar seus lixões, futuros trabalhos poderiam fazer uma análise comparativa das estratégias utilizadas pelos estados que cumpriram suas metas, ou ainda, utilizar uma perspectiva regional de análise de execução financeira e orçamentária. Além disso, a análise de uma política pública através da execução orçamentária permite consolidar seu período de construção, pois algumas vezes levamos a acreditar que seu êxito é creditado a uma única gestão. 


\section{REFERÊNCIAS}

ALAGOAS. Secretaria de Estado da Fazenda. Balanço Geral do estado de Alagoas - 2008. Maceió: Governo do Estado do Alagoas, 2008a. Disponível em:

http://www.sefaz.al.gov.br/legislacao/40-financas/gestao-financeira-orcamentaria/131-balancogeral-do-estado. Acesso em: 3 jan. 2019.

ALAGOAS. Secretaria de Estado da Fazenda. Balanço Geral do estado de Alagoas - 2009. Maceió: Governo do Estado do Alagoas, 2009a. Disponível em:

http://www.sefaz.al.gov.br/legislacao/40-financas/gestao-financeira-orcamentaria/131-balancogeral-do-estado. Acesso em: 3 jan. 2019.

ALAGOAS. Secretaria de Estado da Fazenda. Balanço Geral do estado de Alagoas - 2010. Maceió: Governo do Estado do Alagoas, 2010a. Disponível em:

http://www.sefaz.al.gov.br/legislacao/40-financas/gestao-financeira-orcamentaria/131-balancogeral-do-estado. Acesso em 3 jan. 2019.

ALAGOAS. Secretaria de Estado da Fazenda. Balanço Geral do estado de Alagoas - 2011. Maceió: Governo do Estado do Alagoas, 2011a. Disponível em:

http://www.sefaz.al.gov.br/legislacao/40-financas/gestao-financeira-orcamentaria/131-balancogeral-do-estado. Acesso em 3 jan. 2019.

ALAGOAS. Secretaria de Estado da Fazenda. Balanço Geral do estado de Alagoas - 2012. Maceió: Governo do Estado do Alagoas, 2012a. Disponível em:

http://www.sefaz.al.gov.br/legislacao/40-financas/gestao-financeira-orcamentaria/131-balancogeral-do-estado. Acesso em 3 jan. 2019.

ALAGOAS. Secretaria de Estado da Fazenda. Balanço Geral do estado de Alagoas - 2013. Maceió: Governo do Estado do Alagoas, 2013a. Disponível em:

http://www.sefaz.al.gov.br/legislacao/40-financas/gestao-financeira-orcamentaria/131-balancogeral-do-estado. Acesso em 3 jan. 2019.

ALAGOAS. Secretaria de Estado da Fazenda. Balanço Geral do estado de Alagoas - 2014. Maceió: Governo do Estado do Alagoas, 2014a. Disponível em:

http://www.sefaz.al.gov.br/legislacao/40-financas/gestao-financeira-orcamentaria/131-balancogeral-do-estado. Acesso em 3 jan. 2019.

ALAGOAS. Secretaria de Estado da Fazenda. Balanço Geral do estado de Alagoas - 2015. Maceió: Governo do Estado do Alagoas, 2015a. Disponível em:

http://www.sefaz.al.gov.br/legislacao/40-financas/gestao-financeira-orcamentaria/131-balancogeral-do-estado. Acesso em 3 jan. 2019.

ALAGOAS. Secretaria de Estado da Fazenda. Balanço Geral do estado de Alagoas - 2016. Maceió: Governo do Estado do Alagoas, 2016a. Disponível em: < http://www.sefaz.al.gov.br/legislacao/40-financas/gestao-financeira-orcamentaria/131-balancogeral-do-estado>. Acesso em 3 jan. 2019.

ALAGOAS. Secretaria de Estado da Fazenda. Balanço Geral do estado de Alagoas - 2017. Maceió: Governo do Estado do Alagoas, 2017a. Disponível em:

http://www.sefaz.al.gov.br/legislacao/40-financas/gestao-financeira-orcamentaria/131-balancogeral-do-estado. Acesso em 3 jan. 2019.

ALAGOAS. Decreto ${ }^{\circ} 8.580$ de 28 de maio de 2018. Abre no orçamento vigente da prefeitura municipal de Maceió, em favor de diversos órgãos, um crédito adicional suplementar no valor de r\$4.680.000,00 (quatro milhões, seiscentos e oitenta mil reais). Diário Oficial: Maceió, AL, ano 21, n. 5483, p. 1-16, 2018a. 
ALAGOAS. Lei $\mathbf{n}^{\mathbf{0}} \mathbf{6 . 9 2 3}$, de 8 de fevereiro de 2008. Dispõe, nos termos do artigo 176, $\S 1^{\circ}$, da constituição estadual, sobre o plano plurianual para o período de 2008-2011, e dá outras providências. Maceió: Secretaria de Estado do Planejamento e do Orçamento, 2008 b. Disponível em: http://dados.al.gov.br/dataset/plano-plurianual-ppa. Acesso em 3 jan. 2019.

ALAGOAS. Lei no 6.924, de 8 de fevereiro de 2008. Estima a receita e fixa a despesa do estado de Alagoas para o exercício de 2008. Maceió: Secretaria de Estado do Planejamento, Gestão e Patrimônio, 2008c. Disponível em: http://dados.al.gov.br/dataset/lei-orcamentariaanual-loa. Acesso em: 3 jan. 2019.

ALAGOAS. Lei $\mathbf{n}^{\mathbf{0}} \mathbf{7 . 0 2 9}$, de 19 de janeiro de 2009. Estima a receita e fixa a despesa do estado de Alagoas para o exercício de 2009. Maceió: Secretaria de Estado do Planejamento, Gestão e Patrimônio, 2009b. Disponível em: http://dados.al.gov.br/dataset/lei-orcamentaria-anual-loa. Acesso em 3 jan. 2019.

ALAGOAS. Lei $\mathbf{n}^{\mathbf{0}} \mathbf{7 . 1 4 6}$, de 5 de março de 2010. Estima a receita e fixa a despesa do estado de Alagoas para o exercício 2010. Maceió: Secretaria de Estado do Planejamento, Gestão e Patrimônio, 2010b. Disponível em: http://dados.al.gov.br/dataset/lei-orcamentaria-anual-loa. Acesso em: 3 jan. 2019.

ALAGOAS. Lei $\mathbf{n}^{\mathbf{0}} \mathbf{7 . 2 3 4}$, de 4 de março de 2011. Estima a receita e fixa a despesa do estado de Alagoas para o exercício de 2011. Maceió: Secretaria de Estado do Planejamento, Gestão e Patrimônio, 2011b. Disponível em: http://dados.al.gov.br/dataset/lei-orcamentaria-anual-loa. Acesso em: 3 jan. 2019.

ALAGOAS. Lei $\mathbf{n}^{\mathbf{0}}$ 7.317, de 28 de dezembro de 2011. Estima a receita e fixa a despesa do estado de Alagoas para o exercício financeiro de 2012. Maceió: Secretaria de Estado do Planejamento, Gestão e Patrimônio, 2011c. Disponível em: http://dados.al.gov.br/dataset/leiorcamentaria-anual-loa. Acesso em: 3 jan. 2019.

ALAGOAS. Lei $\mathbf{n}^{\mathbf{0}} \mathbf{7 . 3 3 3}$, de 5 de janeiro de 2012. Dispõe sobre o plano plurianual para o período de 2012-2015, nos termos do art. 176, § $1^{\circ}$ da constituição estadual, e dá outras providências. Maceió: Secretaria de Estado do Planejamento, Gestão e Patrimônio, 2012b. Disponível em: http://dados.al.gov.br/dataset/plano-plurianual-ppa. Acesso em: 3 jan. 2019.

ALAGOAS. Lei $\mathbf{n}^{\mathbf{0}} \mathbf{7 . 4 4 6}$, de 10 de janeiro de 2013. Estima a receita e fixa a despesa do estado de Alagoas para o exercício financeiro de 2013. Maceió: Secretaria de Estado do Planejamento, Gestão e Patrimônio, 2013b. Disponível em: http://dados.al.gov.br/dataset/lei-orcamentariaanual-loa. Acesso em: 8 jan. 2019.

ALAGOAS. Lei $\mathbf{n}^{\mathbf{0}} \mathbf{7 . 5 7 9}$, de 27 de janeiro de 2014. Estima a receita e fixa a despesa do estado de Alagoas para o exercício financeiro de 2014. Maceió: Secretaria de Estado do Planejamento, Gestão e Patrimônio, 2014b. Disponível em: http://dados.al.gov.br/dataset/lei-orcamentariaanual-loa. Acesso em: 8 jan. 2019.

ALAGOAS. Lei no 7.691, de 6 de abril de 2015. Estima a receita e fixa a despesa do estado de Alagoas para o exercício financeiro de 2015. Maceió: Secretaria de Estado do Planejamento, Gestão e Patrimônio, 2015b. Disponível em: http://dados.al.gov.br/dataset/lei-orcamentariaanual-loa. Acesso em: 12 jan. 2019.

ALAGOAS. Lei $\mathbf{n}^{\mathbf{0}} \mathbf{7 . 7 9 8}$, de 6 de abril de 2016. Dispõe sobre o plano plurianual para o período de 2016-2019, nos termos do art. 176, § 1º da constituição estadual, e dá outras providências. Maceió: Secretaria de Estado do Planejamento, Gestão e Patrimônio, 2016b. Disponível em: http://dados.al.gov.br/dataset/plano-plurianual-ppa. Acesso em: 13 jan. 2019. 
ALAGOAS. Lei $\mathbf{n}^{\mathbf{0}} \mathbf{7 . 7 9 9}$, de 6 de abril de 2016. Estima a receita e fixa a despesa do estado de Alagoas para o exercício financeiro de 2016. Maceió: Secretaria de Estado do Planejamento, Gestão e Patrimônio, 2016c. Disponível em: http://dados.al.gov.br/dataset/lei-orcamentariaanual-loa. Acesso em 6 jan. 2019.

ALAGOAS. Lei $\mathbf{n}^{\mathbf{0}} \mathbf{7 . 8 7 1}$, de 19 de janeiro de 2017. Estima a receita e fixa a despesa do estado de Alagoas para o exercício financeiro de 2017. Maceió: Secretaria de Estado do Planejamento, Gestão e Patrimônio, 2017b. Disponível em: http://dados.al.gov.br/dataset/lei-orcamentariaanual-loa. Acesso em: 6 jan. 2019.

ALAGOAS. Lei $\mathbf{n}^{\mathbf{0}} \mathbf{7 . 9 8 6}$, de 23 de janeiro de 2018. Estima a receita e fixa a despesa do estado de Alagoas para o exercício financeiro de 2018. Maceió: Secretaria de Estado do Planejamento, Gestão e Patrimônio, 2018b. Disponível em: http://dados.al.gov.br/dataset/lei-orcamentariaanual-loa. Acesso em: 24 jan. 2019.

ALAGOAS. Lei no 7749, de 13 de outubro de 2015. Dispõe sobre a Política Estadual de Resíduos Sólidos e Inclusão Produtiva, e dá outras providências. Maceió, 2015c. Disponível em: http://www.residuossolidos.al.gov.br/vgmidia/arquivos/184_ext_arquivo.pdf. Acessado em: 24 jan. 2019.

ALBUQUERQUE, C.; MEDEIROS, M.; FEIJÓ, P. Gestão de finanças públicas. $2^{\mathrm{a}}$ edição. Brasília: Cidade Gráfica, 2008.

BRASIL. Lei $\mathbf{n}^{\mathbf{0}}$ 12.305, de 2 de agosto de 2010. Institui a Política Nacional de Resíduos Sólidos; altera a Lei no 9.605, de 12 de fevereiro de 1998; e dá outras providências. Brasília, DF: Presidência da República, [2010]. Disponível em: http://www.planalto.gov.br/ccivil_03/_ato2007-2010/2010/lei/112305.htm. Acesso em: 23 jan. 2019.

BRASIL. Ministério da Transparência e Controladoria-Geral da União. Secretaria Federal de Controle Interno. Relatório de avaliação por área de gestão $\mathbf{n}^{0}$ 9. Resíduos Sólidos. Brasília, out. 2017.

BRASIL. [Constituição (1988)]. Constituição da República Federativa do Brasil de 1988. Brasília, DF: Presidência da República, [2019]. Disponível em: http://www.planalto.gov.br/ccivil_03/constituicao/constituicao.htm. Acesso em: Acesso em: 23 jan. 2019.

CONFEDERAÇÃO NACIONAL DE MUNICÍPIO. Observatório dos Lixões. Brasília: CNM, 2019. Disponível em: http://www.lixoes.cnm.org.br/. Acesso em: 4 jan. 2019.

CONFEDERAÇÃO NACIONAL DE MUNICÍPIOS. Pesquisa sobre Gestão Municipal de Resíduos Sólidos: Análise dos Resultados Prévio. Brasília: CNM, 2017. Disponível em: www.cnm.org.br. Acesso em: 7 jan. 2019.

FLORAM ENGENHARIA E MEIO AMBIENTE. Plano Estadual de Resíduos Sólidos (PERS) - Volume 1 (Técnico) - Tomo I. Maceió: SERMARH, 2016c. 294 p. v.1, t. 1. Disponível em: http://www.residuossolidos.al.gov.br/planos/estadual Acesso em: 15 jan. 2019.

FLORAM ENGENHARIA E MEIO AMBIENTE. Plano Estadual de Resíduos Sólidos (PERS) - Volume 1 (Técnico) - Tomo II. Maceió: SERMARH, 2016a. 502 p. v. 1, t. 2. Disponível em: http://www.residuossolidos.al.gov.br/planos/estadual. Acesso em: 9 jan. 2019. 
FLORAM ENGENHARIA E MEIO AMBIENTE. Plano Estadual de Resíduos Sólidos (PERS) - Volume 1 (Técnico) - Tomo III. Maceió: SERMARH, 2016b. 281 p. v. 1, t. 3. Disponível em: http://www.residuossolidos.al.gov.br/planos/estadual Acesso em: 9 jan. 2019.

GARSON, S. Planejamento, orçamento e gasto com políticas públicas: uma metodologia de apuração para Estados e Municípios. Porto Alegre: Editora Fi, 2018.

LUNA, Mozart. Conorte escolhe área para transbordo e anuncia fim dos lixões. Gazeta web; Meio Ambiente \& Turismo, out. 2017. Disponível em: http://meioambienteeturismo.blogsdagazetaweb.com/2017/10/07/conorte-escolhe-area-paratransbordo-e-anuncia-fim-dos-lixoes/. Acesso em: 30 jan. 2019.

INSTITUTO DE PESQUISA ECONÔMICA APLICADA. Brasil 2035: cenários para o desenvolvimento. Brasília: IPEA, 2017.

LIMA, E. Curso de Finanças Públicas: uma abordagem contemporânea. São Paulo: Atlas, 2015.

MAIELLO, A.; BRITTO, A.; VALLE, T. Implementação da Política Nacional de Resíduos Sólidos. Revista de Administração Pública, Rio de Janeiro, v. 52, n. 1, p. 24-51, jan./fev. 2018. Disponível em: http://www.scielo.br/pdf/rap/v52n1/1982-3134-rap-52-01-24.pdf. Acesso em: 30 jan. 2019.

MANNARINO, C.; FERREIRA, J.; GANDOLLA, M. Contribuições para a evolução do gerenciamento de resíduos sólidos urbanos no Brasil com base na experiência Europeia. Engenharia Sanitária Ambiental, Rio de Janeiro, v. 21, n. 2, p. 379-385, abr./jun. 2016. Disponível em: http://www.scielo.br/pdf/esa/v21n2/1809-4457-esaS1413_41522016146475.pdf. Acesso em: 30 jan. 2019.

MARCHI, C. Novas perspectivas na gestão do saneamento: apresentação de um modelo de destinação final de resíduos sólidos urbanos. Revista Brasileira de Gestão Urbana, Curitiba, v. 7, n. 1, p. 91-105, jan./abr. 2015. Disponível em: http://www.scielo.br/pdf/urbe/v7n1/21753369-urbe-7-1-0091.pdf. Acesso em: 30 jan. 2019.

NASCIMENTO, V et al. Evolução e desafios no gerenciamento dos resíduos sólidos urbanos no Brasil. Revista Ambiente e Água, Taubaté, v. 10, n. 4, p. 889-902, out./dec. 2015. Disponível em: http://www.scielo.br/pdf/ambiagua/v10n4/1980-993X-ambiagua-10-04-00889.pdf. Acesso em: 30 jan. 2019.

SARAVIA, E. Introdução à teoria da política pública. In: SARAVIA, E.; FERRAREZI, E. (org.). Políticas públicas - coletânea. Brasília: ENAP, 2006.

SOUZA, C. Políticas Públicas: uma revisão da literatura. Sociologias, Porto Alegre, ano 8, n. 16, p. 20-45, jul./dez. 2006. Disponível em: http://www.scielo.br/pdf/soc/n16/a03n16. Acesso em: 30 jan. 2019.

TRONCO, G. O guia de políticas públicas para estudantes e gestores. Porto Alegre: Jacarta Produções, 2018.

Artigo recebido em: 2019-05-30

Artigo reapresentado em: 2019-07-15

Artigo aceito para publicação em: 2019-09-06 